\title{
DIVERGÊNCIA GENÉTICA ENTRE CULTIVARES DE GIRASSOL NO PLANALTO NORTE CATARINENSE
}

\section{GENETIC DIVERGENCE AMONG SUNFLOWER CULTIVARS IN THE NORTH PLATEAU OF SANTA CATARINA STATE}

\author{
Gilcimar Adriano VOGT ${ }^{1}$ \\ Alvadi Antonio BALBINOT JÚNIOR ${ }^{2}$ \\ Adriano Martinho de SOUZA ${ }^{3}$
}

\begin{abstract}
RESUMO
O objetivo deste trabalho foi estimar a divergência genética entre 17 cultivares de girassol com base em caracteres morfológicos e fisiológicos. O experimento foi conduzido em área experimental localizada no município de Papanduva, SC, na safra 2008/2009. O delineamento experimental utilizado foi de blocos casualizados, com quatro repetições. A análise multivariada foi empregada para estimar a divergência genética entre os cultivares, utilizando-se os métodos do UPGMA e Tocher, com base na distância generalizada de Mahalanobis $\left(D^{2}\right)$, além de variáveis canônicas. Análises de variância univariada e multivariada revelaram diferenças entre os cultivares. Os cultivares foram agrupados em três grupos. As características altura de planta e dias para florescimento contribuíram com grande parte da divergência observada.

Palavras-chave: variabilidade genética; Helianthus annus; $\mathrm{D}^{2}$ análises.
\end{abstract}

\begin{abstract}
The objective of this work was to evaluate the genetic divergence among 17 cultivars of sunflower. The experiment was carried out in Papanduva, North Plateau of Santa Catarina State, Brazil, in 2008/2009 cropping season. The experimental design was a randomized block with four replications. The multivariate was used to evaluate the divergence among the cultivars by canonic variable and cluster analysis (UPGMA and Tocher), based on the generalized Mahalanobis Distance $\left(\mathrm{D}^{2}\right)$. Univariate and multivariate analyses of variance showed differences among cultivars. The cultivars were grouped in tree clusters. The plant height and days until the flowering showed high contribution towards genetic divergence.

Key-words: genetic variability; Helianthus annus; $D^{2}$ analysis.
\end{abstract}

\footnotetext{
${ }^{1}$ M.Sc. Pesquisador da Epagri - Estação Experimental de Canoinhas, BR-280, km 219,5, CEP 89460-000, Canoinhas, Santa Catarina, Brasil. E-mail: gilcimar@epagri.sc.gov.br. Autor para correspondência.

${ }^{2}$ D.Sc. Pesquisador da Epagri - Estação Experimental de Canoinhas, Canoinhas, Santa Catarina, Brasil. E-mail: balbinot@epagri.sc.gov.br.

${ }^{3}$ M.Sc. Pesquisador da Epagri - Estação Experimental de Canoinhas, Canoinhas, Santa Catarina, Brasil. E-mail: adriano@epagri.sc.gov.br.
} 
VOGT, G. A. et al. Divergência genética entre cultivares de girasol...

\section{INTRODUÇÃO}

O cultivo do girassol tem se mostrado uma opção econômica em sistemas de rotação com outras culturas de grãos, e vem despertando o interesse de agricultores, técnicos e empresas, devido à possibilidade de utilizar seu óleo como matéria-prima para fabricação de biodiesel (Backes et al., 2008).

O estudo das características morfológicas das culturas através da utilização de técnicas estatísticas multivariadas é importante para se estimar a divergência genética do conjunto de cultivares disponíveis (Elias et al., 2007) e tem sido empregada em vários trabalhos em diversas culturas, como feijão (Benin et al., 2002; Cargnelutti Filho et al., 2008), trigo (Bertan et al., 2006), aveia (Benin et al., 2003) e milho (Miranda et al., 2003; Vieira et al., 2005).

A divergência genética tem sido estudada visando a seleção de genitores para a formação de híbridos, ou mesmo para formação de novas populações segregantes oriundas do intercruzamento de genótipos divergentes (Bertini et al., 2009). Vários trabalhos que avaliaram a divergência genética em girassol foram realizados utilizando caracteres morfoagronômicos (Subrahmanyam et al., 2003; Messetti \& Padovani, 2009; Amorim et al., 2007; Mohan \& Seetharam, 2005; Arshad et al., 2007).

Entre os procedimentos estatísticos mais utilizados para estimar a distância genética com base em caracteres morfológicos estão as estimativas de distâncias entre cada par de genótipos e sua apresentação em uma matriz simétrica. A partir da obtenção desta, sua interpretação pode ser facilitada pela utilização de métodos de agrupamento, que tem por finalidade separar um grupo original em subgrupos, de forma a obter homogeneidade dentro e heterogeneidade entre os subgrupos (Bertan et al., 2006). Este conhecimento se traduz na determinação da divergência ou dissimilaridade genética.

A determinação da dissimilaridade genética por meio de análise simultânea de diversos caracteres nos genótipos é vantajosa na identificação da variabilidade genética (Moura et al., 1999). A classificação dos genótipos utilizando os recursos da análise multivariada tem oferecido contribuições para o melhoramento genético de várias culturas (Santos et al., 2000). A obtenção destas e outras informações tem sido decisiva para dar suporte tecnológico ao desenvolvimento da cultura do girassol, garantindo melhores produtividades e retornos econômicos competitivos (Porto et al., 2007).

O objetivo deste trabalho foi estimar a divergência genética entre 17 cultivares de girassol com base em descritores morfológicos e fisiológicos, utilizando-se técnicas de análise multivariada.

\section{MATERIAL E MÉTODOS}

O experimento foi conduzido no Campo Experimental Salto Canoinhas, município de Papanduva/SC, em área da Epagri/Estação Experimental de Canoinhas. O clima da região é úmido com verões amenos, do tipo $\mathrm{Cfb}$, segundo a classificação de Köppen (Ide et al., 1980). O solo do local é classificado como Latossolo Bruno Distrófico (EMBRAPA, 1999). A altitude da área experimental é de aproximadamente $810 \mathrm{~m}$ e as coordenadas geoprocessadas do local são longitude $50^{\circ} 16^{\prime} 37^{\prime \prime}$ Oeste e latitude $26^{\circ} 22^{\prime} 15^{\prime \prime}$ Sul.

Foram avaliados 17 cultivares de girassol pertencentes a diferentes programas de melhoramento genético (Tabela 1). $O$ delineamento adotado foi de blocos casualizados, com quatro repetições. A parcela foi composta de quatro linhas de $5 \mathrm{~m}$, espaçadas em $0,9 \mathrm{~m}$. Nas avaliações considerou-se apenas a área útil, composta pelas duas linhas centrais de cada unidade experimental.

A semeadura ocorreu em 03/11/2008 sob sistema de plantio direto, em palha de aveia preta e ervilhaca. Utilizou-se a densidade de $\mathbf{4 0}$ mil plantas $\mathrm{ha}^{-1}$. As sementes foram tratadas com o inseticida Thiodicarb. As adubações de base e cobertura foram realizadas de acordo com as recomendações técnicas para a cultura (Sociedade..., 2004). A adubação de base foi composta por $200 \mathrm{~kg} \mathrm{ha}^{-1}$ de 4-20-20 de $\mathrm{N}-\mathrm{P}_{2} \mathrm{O}_{5}-\mathrm{K}_{2} \mathrm{O}$, aplicados nas linhas e $9 \mathrm{~kg}$ ha $^{-1}$ de bórax, aplicados em mistura com glyphosate e óleo mineral por ocasião da dessecação da cobertura vegetal. Quando as plantas de girassol apresentavam, em média, cinco folhas expandidas, realizou-se a adubação de cobertura com $80 \mathrm{~kg} \mathrm{ha}^{-1}$ de uréia, aplicada em superfície ao lado das fileiras. Foram avaliadas as seguintes características:

- Altura de planta (AP, em $\mathrm{cm})$ : medida do solo até a inserção do capítulo, em dez plantas por parcela, presentes na área útil, durante a fase de maturação fisiológica;

- Diâmetro da haste $(\mathrm{DH}$, em $\mathrm{cm})$ : medido a $10 \mathrm{~cm}$ do solo, em dez plantas por parcela, na fase de maturação fisiológica;

- Número de folhas (NF): observado em dez plantas por parcela, na fase de maturação fisiológica;

- Curvatura do capítulo (CC): avaliação visual, realizada por dois avaliadores utilizando escala de notas de 1 a 7 , sendo 1 para inclinada, 2 vertical, 3 semi-invertida com haste ereta, 4 semi-invertida com haste recurvada, 5 vertical com haste ereta, 6 invertida com haste recurvada e 7 reflexa, avaliadas na fase de maturação fisiológica;

- Dias entre a semeadura e o florescimento (DF, em dias): anotado quando $50 \%$ das plantas da parcela útil encontravam-se em floração plena;

- Massa de mil aquênios (MMA, em g): obtido pela pesagem de mil aquênios dos capítulos colhidos por parcela;

- Número de grãos por capítulo (NGC): razão entre o número de grãos pelo número de capítulos colhidos; 
VOGT, G. A. et al. Divergência genética entre cultivares de girasol...

- Número de capítulos por planta (NCP): obtido pela razão entre o número de capítulos colhidos pelo número de plantas da parcela útil;

- Diâmetro do capítulo (DC, em $\mathrm{cm})$ : diâmetro médio de todos os capítulos colhidos;
- Porcentagem de capítulos com sintomas de podridão branca (Sclerotinia sclerotiorum) (SCL);

- Produtividade de grãos (REND, em $\mathrm{kg} \mathrm{ha}^{-1}$ ): estimada pela colheita dos grãos da área útil, sendo os dados corrigidos para $11 \%$ de umidade.

TABELA 1 - Cultivares de girassol utilizados no experimento.

\begin{tabular}{lllll}
\hline & Cultivares & Tipo & Empresa & País \\
\hline 1 & Charrua & Híbrido triplo & Advanta & Argentina \\
2 & Agrobel 962 & Híbrido triplo & La Tijereta & Argentina \\
3 & Agrobel 960 & Híbrido triplo & La Tijereta & Argentina \\
4 & Agrobel 972 & Híbrido simples & La Tijereta & Argentina \\
5 & Dow M734 & Híbrido simples & Dow Agrosciences & Argentina \\
6 & Dow MG 2 & Híbrido simples & Dow Agrosciences & Argentina \\
7 & Aguará 3 & Híbrido simples & Advanta & Argentina \\
8 & Aguará 4 & Híbrido simples & Advanta & Argentina \\
9 & Hélio 884 & Híbrido simples & Helianthus do Brasil & Argentina \\
10 & Embrapa 122 & Variedade & Embrapa & Brasil \\
11 & IAC larama & Variedade & IAC & Brasil \\
12 & Hélio 360 & Híbrido triplo & Helianthus do Brasil & Argentina \\
13 & Hélio 863 & Híbrido simples & Helianthus do Brasil & Argentina \\
14 & Hélio 251 & Híbrido simples & Helianthus do Brasil & Argentina \\
15 & Hélio 358 & Híbrido simples & Helianthus do Brasil & Argentina \\
16 & Hélio 250 & Híbrido simples & Helianthus do Brasil & Argentina \\
17 & Hélio 885 & Híbrido simples & Helianthus do Brasil & Argentina \\
\hline
\end{tabular}

Os dados foram submetidos à análise de variância e ao teste $F$. Quando constatado efeito significativo de tratamentos, as médias foram agrupadas pelo teste de Scott-Knott a $5 \%$ de probabilidade. A dissimilaridade genética entre os cultivares foi estimada pelo uso da distância generalizada de Mahalanobis $\left(D^{2}\right)$, a partir das médias dos cultivares e da matriz de covariância residual, de acordo com Cruz \& Regazzi (2001). No agrupamento dos cultivares, foi empregado os métodos de agrupamento de Tocher, ligação entre grupo (UPGMA) e variáveis canônicas, para a formação do dendrograma e dispersão gráfica bidimensional, com auxílio do programa computacional Genes (Cruz, 2008).

\section{RESULTADOS E DISCUSSÃO}

$O$ teste $F$ indicou que houve diferenças entre cultivares de girassol em nível de $1 \%$ de probabilidade para todas as variáveis analisadas (Tabela 2). Isto significa que há variabilidade genética entre os cultivares avaliados e é um indicativo de que as constituições genéticas são divergentes para os caracteres morfológicos avaliados. Os coeficientes de variação foram de baixa magnitude, oscilando de 2,4 a $18,2 \%$ para DF e NGC, respectivamente (Tabela 2), revelando adequada precisão experimental.

As médias dos caracteres agronômicos dos cultivares foram agrupadas pelo teste de Scott \& Knott a $5 \%$ de probabilidade (Tabela 2). As maiores discrepâncias entre tratamentos foram observadas nas variáveis DF e AP (Tabela 2), formando cinco e quatro grupos, respectivamente.

Para DF, o genótipo Embrapa 122 foi o mais precoce e os cultivares Aguará 3, Aguará 4, Charrua, Dow MG 2 e Agrobel 972 os mais tardios, resultado similar aos resultados obtidos por Balbinot Jr. et al. (2009) e Backes et al. (2008). Para AP, os cultivares Hélio 250 e Agrobel 960 foram os mais baixos (121 e $124 \mathrm{~cm}$, respectivamente) e Aguará 4, Charrua e Aguará 3 os mais altos, apresentando AP superior a $172 \mathrm{~cm}$. Backes et al. (2008) não detectou diferenças significativas para AP para os mesmos cultivares em cultivo na safrinha no Planalto Norte Catarinense.

Para as variáveis NF, CC, MMA e REND houve a formação de três grupos. O NF médio entre os cultivares de girassol foi de 31 (Tabela 2), similar ao obtido por Amorim et al. (2007) e Amorim et al. (2008). As notas de CC variaram entre 5,0 e 2,8, ficando a maioria dos cultivares com curvatura do capítulo semi-invertida com haste ereta (nota 3 ) e semi-invertida com haste recurvada (nota 4). O genótipo Embrapa 122 apresentou CC vertical com haste ereta (nota 5), como também relatado por Amorim et al. (2008), característica que pode ocasionar redução da produtividade devido às perdas por ataque de pássaros. Quanto ao MMA, os cultivares apresentaram na média $45,8 \mathrm{~g}$, inferior aos valores obtidos por Backes et al. (2008) e Balbinot Jr. et al. (2009), mas superior aos resultados de Amorim et al. (2008). 
VOGT, G. A. et al. Divergência genética entre cultivares de girasol...

TABELA 2 - Distribuição dos cultivares de girassol em diferentes grupos de similaridade estabelecidos pelo método de Tocher e médias dos 11 caracteres agronômicos avaliados para os 17 cultivares de girassol.

\begin{tabular}{|c|c|c|c|c|c|c|c|c|c|c|c|c|}
\hline Cultivares & Tocher & & $\begin{array}{l}\text { AP } \\
(\mathrm{cm}) \\
\end{array}$ & & $\begin{array}{c}\mathrm{DH} \\
(\mathrm{mm})\end{array}$ & & $\begin{array}{c}\text { NF } \\
\text { (unid) }\end{array}$ & & $\begin{array}{c}\mathrm{CC} \\
\text { (nota) }\end{array}$ & & $\begin{array}{c}\mathrm{DF} \\
\text { (dias) } \\
\end{array}$ & \\
\hline Aguará 4 & 1 & & 177 & $\overline{a^{1}}$ & 19,1 & $\bar{a}$ & 34 & $\mathrm{~b}$ & 3,0 & $\bar{c}$ & 74 & $\bar{a}$ \\
\hline Dow MG 2 & 1 & & 166 & $b$ & 17,4 & $b$ & 38 & a & 3,0 & $\mathrm{c}$ & 73 & a \\
\hline Agrobel 962 & 1 & & 156 & $b$ & 19,0 & a & 31 & $\mathrm{c}$ & 3,0 & $\mathrm{c}$ & 69 & $b$ \\
\hline Hélio 884 & 1 & & 165 & $b$ & 16,2 & $b$ & 33 & $b$ & 3,3 & $\mathrm{C}$ & 69 & $\mathrm{~b}$ \\
\hline Aguará 3 & 1 & & 172 & $a$ & 21,1 & $a$ & 35 & $b$ & 2,8 & C & 75 & a \\
\hline Charrua & 1 & & 175 & $\mathrm{a}$ & 20,2 & a & 34 & $b$ & 3,0 & C & 74 & a \\
\hline Agrobel 972 & 1 & & 161 & $\mathrm{~b}$ & 18,6 & $a$ & 30 & $\mathrm{C}$ & 3,0 & $\mathrm{C}$ & 72 & $\mathrm{a}$ \\
\hline Dow M734 & 2 & & 142 & $c$ & 17,2 & $\mathrm{~b}$ & 32 & $b$ & 4,0 & $b$ & 67 & c \\
\hline Hélio 863 & 2 & & 138 & $\mathrm{c}$ & 16,9 & $b$ & 29 & $\mathrm{c}$ & 3,3 & $\mathrm{c}$ & 62 & $d$ \\
\hline Hélio 251 & 2 & & 137 & $c$ & 18,2 & $b$ & 28 & $\mathrm{C}$ & 3,5 & $c$ & 67 & C \\
\hline Hélio 358 & 2 & & 133 & $c$ & 17,3 & $b$ & 34 & $b$ & 4,0 & $b$ & 66 & c \\
\hline Hélio 360 & 2 & & 138 & $c$ & 18,0 & $b$ & 31 & $\mathrm{C}$ & 3,8 & $b$ & 64 & c \\
\hline Hélio 885 & 2 & & 135 & $c$ & 19,4 & a & 29 & c & 3,0 & c & 71 & $b$ \\
\hline IAC larama & 2 & & 134 & $c$ & 17,0 & $b$ & 29 & $\mathrm{C}$ & 3,8 & $b$ & 65 & C \\
\hline Agrobel 960 & 2 & & 124 & $\mathrm{~d}$ & 18,1 & $b$ & 27 & $\mathrm{c}$ & 3,5 & $c$ & 66 & c \\
\hline Hélio 250 & 2 & & 121 & $\mathrm{~d}$ & 17,0 & $\mathrm{~b}$ & 30 & $\mathrm{C}$ & 3,8 & $\mathrm{~b}$ & 62 & $\mathrm{~d}$ \\
\hline Embrapa 122 & 3 & & 141 & $c$ & 15,6 & $\mathrm{~b}$ & 30 & $\mathrm{C}$ & 5,0 & $a$ & 59 & $\mathrm{e}$ \\
\hline Média geral & ----- & & 148 & & 18,0 & & 31 & & 3,4 & & 68 & \\
\hline CV (\%) & ----- & & 3,8 & & 7,1 & & 6,2 & & 10,5 & & 2,4 & \\
\hline DMS & ----- & & 15 & & 3,3 & & 5 & & 0,9 & & 4 & \\
\hline $\mathrm{F}$ (tratamentos) & & & $41,27^{\star *}$ & & $5,10^{* *}$ & & $9,23^{* *}$ & & $9,80^{* *}$ & & $35,84^{* *}$ & \\
\hline Cultivares & $\begin{array}{l}\text { MMA } \\
(\mathrm{g})\end{array}$ & & $\begin{array}{l}\text { NGC } \\
\text { (unid) }\end{array}$ & & $\begin{array}{l}\mathrm{NCP} \\
\text { (unid) }\end{array}$ & & $\begin{array}{c}\mathrm{DC} \\
(\mathrm{cm})\end{array}$ & & $\begin{array}{l}\text { SCL } \\
(\%)\end{array}$ & & $\begin{array}{l}\text { REND } \\
\left(\mathrm{kg} \mathrm{ha}^{-1}\right)\end{array}$ & \\
\hline Aguará 4 & 40,2 & $\mathrm{C}$ & 1104 & $a$ & 1,00 & a & 17,9 & a & 0,0 & $b$ & 1916 & $a$ \\
\hline Dow MG 2 & 47,2 & $\mathrm{~b}$ & 924 & a & 1,00 & a & 16,4 & a & 0,0 & $b$ & 1904 & a \\
\hline Agrobel 962 & 47,6 & $\mathrm{~b}$ & 892 & $a$ & 1,00 & $a$ & 16,7 & a & 1,6 & $\mathrm{~b}$ & 1777 & a \\
\hline Hélio 884 & 46,6 & $b$ & 832 & a & 1,00 & a & 16,5 & a & 0,0 & $b$ & 1707 & a \\
\hline Aguará 3 & 47,5 & $\mathrm{~b}$ & 893 & a & 1,00 & a & 18,1 & a & 1,9 & $b$ & 1596 & a \\
\hline Charrua & 39,0 & c & 914 & a & 1,00 & a & 16,8 & a & 0,0 & $b$ & 1571 & a \\
\hline Agrobel 972 & 36,7 & $\mathrm{C}$ & 776 & $\mathrm{~b}$ & 1,00 & $\mathrm{a}$ & 15,5 & $\mathrm{~b}$ & 0,0 & $\mathrm{~b}$ & 1315 & $\mathrm{~b}$ \\
\hline Dow M734 & 57,9 & $a$ & 754 & $b$ & 1,00 & a & 16,2 & $a$ & 0,0 & $b$ & 1962 & $a$ \\
\hline Hélio 863 & 44,6 & c & 883 & $\mathrm{a}$ & 0,99 & a & 16,0 & a & 5,6 & $b$ & 1656 & a \\
\hline Hélio 251 & 47,1 & $b$ & 704 & $\mathrm{~b}$ & 1,03 & a & 16,3 & a & 5,6 & $b$ & 1450 & $b$ \\
\hline Hélio 358 & 51,9 & $b$ & 672 & $\mathrm{~b}$ & 0,99 & a & 14,5 & $b$ & 4,4 & $\mathrm{~b}$ & 1448 & $b$ \\
\hline Hélio 360 & 40,7 & c & 767 & $\mathrm{~b}$ & 1,00 & a & 16,1 & a & 2,8 & $b$ & 1383 & $b$ \\
\hline Hélio 885 & 42,7 & $\mathrm{C}$ & 754 & $\mathrm{~b}$ & 1,00 & a & 14,8 & $b$ & 8,4 & $b$ & 1252 & $b$ \\
\hline IAC larama & 50,6 & $b$ & 636 & $\mathrm{~b}$ & 0,97 & a & 16,9 & a & 1,6 & $b$ & 1180 & $b$ \\
\hline Agrobel 960 & 40,8 & c & 701 & $\mathrm{~b}$ & 1,00 & a & 17,0 & a & 1,5 & $b$ & 1161 & $b$ \\
\hline Hélio 250 & 40,0 & $\mathrm{C}$ & 498 & $\mathrm{~b}$ & 1,00 & $a$ & 15,2 & $\mathrm{~b}$ & 0,0 & $\mathrm{~b}$ & 804 & $\mathrm{C}$ \\
\hline Embrapa 122 & 57,3 & $a$ & 611 & $\mathrm{~b}$ & 0,87 & $\mathrm{~b}$ & 14,9 & $\mathrm{~b}$ & 26,8 & $\mathrm{a}$ & 1305 & $\mathrm{~b}$ \\
\hline Média geral & 45,8 & & 783 & & 1,0 & & 16,2 & & 3,5 & & 1493 & \\
\hline CV $(\%)$ & 13,5 & & 18,2 & & 3,7 & & 7,2 & & 3,1 & & 15,0 & \\
\hline DMS & 15,9 & & 369 & & 0,09 & & 3,0 & & 0,1 & & 577 & \\
\hline $\mathrm{F}$ (tratamentos) & $3,99^{*}$ & & $4,13^{* *}$ & & $3,40 * *$ & & $3,01^{* *}$ & & $3,59^{* *}$ & & $7,83^{* *}$ & \\
\hline
\end{tabular}

Altura de planta (AP), diâmetro da haste (DH), número de folhas (NF), curvatura do caule (CC), dias para florescimento (DF), massa de mil aquênios (MMA), número de grãos por capítulo (NGC), número de capítulos por planta (NCP), diâmetro do capítulo (DC), porcentagem de capítulos com sintomas de podridão branca (SCL) e rendimento de grãos (REND). ${ }^{1}$ Médias seguidas da mesma letra, nas colunas, pertencem ao mesmo grupo pelo teste de agrupamento de Scott \& Knott, a $5 \%$ de probabilidade. ${ }^{* *} \mathrm{e}^{*}$ significativos a 1 e $5 \%$ de probabilidade, respectivamente, pelo teste $\mathrm{F}$. 
VOGT, G. A. et al. Divergência genética entre cultivares de girasol...

O REND médio entre os cultivares avaliados foi de $1493 \mathrm{~kg} \mathrm{ha}^{-1}$ (Tabela 2). Os cultivares Dow M734, Aguará 4, Dow MG 2, Agrobel 962, Hélio 884, Hélio 863, Aguará 3 e Charrua foram os mais produtivos, obtendo REND entre $1962 \mathrm{~kg} \mathrm{ha}^{-1}$ (Dow M734) e $1571 \mathrm{~kg} \mathrm{ha}^{-1}$ (Charrua) (Tabela 2). Balbinot Jr. et al. (2009), em ensaio de avaliação de cultivares na safra 2007/2008 para a mesma época de semeadura e região obteve produtividade média similar deste ensaio, sendo os cultivares Dow M734 e Dow MG 2, também os mais produtivos. O cultivar Hélio 250 foi o que obteve o menor REND (804 kg ha ${ }^{-1}$ ) e reduzido NGC (498), apesar de apresentar DC similar aos híbridos Agrobel 972, Hélio 358 e Hélio 885. Isso ocorreu por deficiência no enchimento dos grãos, apresentando no centro do capítulo aquênios com reduzida massa.

Para as variáveis $\mathrm{DH}, \mathrm{NGC}, \mathrm{NCP}, \mathrm{SCL}$ e DC observaram-se a formação de dois grupos. O DH médio entre os cultivares foi de $18 \mathrm{~mm}$ (Tabela 2 ), inferior aos dados médios obtidos por Amorim et al. (2007), Amorim et al. (2008) e Backes et al. (2008). Os dados médios de NGC e NCP foram 783 e 1,0, respectivamente. O cultivar Embrapa 122 obteve NCP de 0,87 , apresentando plantas que não apresentaram inflorescência, devido supressão de crescimento de plantas que apresentaram emergência tardia e alta severidade de mofo-branco em algumas plantas. Outrossim, no ensaio conduzido por Backes et al. (2008) na mesma região de cultivo, alguns cultivares também apresentaram NCP inferior a 1. A maior incidência de mofo branco no capítulo (SCL) foi observada no genótipo Embrapa 122 (26,8\%), mostrando ser um genótipo muito susceptível à podridão branca $(S$. sclerotiorum), como também relatado por Backes et al. (2008).

Os cultivares Hélio 358, Hélio 885 , Embrapa 122, Hélio 250 e Agrobel 972 apresentaram menor DC (Tabela 2), o que, segundo Bruginski \& Pissaia (2002) e Amorim et al. (2008) proporcionam efeito direto positivo sobre a produtividade de grãos.

Os cultivares que associaram maior DC e MMA e elevado NGC apresentaram os maiores REND. Amorim et al. (2008) relatam que existe correlações significativas e efeitos diretos positivos entre produtividade de grãos, diâmetro do capítulo, porcentagem de grãos normais e a massa de mil grãos, podendo ser utilizados na seleção indireta visando o desenvolvimento e novos genótipos.

O resultado da distribuição dos grupos com padrões de comportamento similares pelo Método de Tocher (Tabela 2) e análise de agrupamento UPGMA (Figura 1), realizado a partir das distâncias de Mahalanobis $\left(D^{2}\right)$, separaram os cultivares em três grupos com comportamento similar dentro do grupo e divergentes entre grupos.

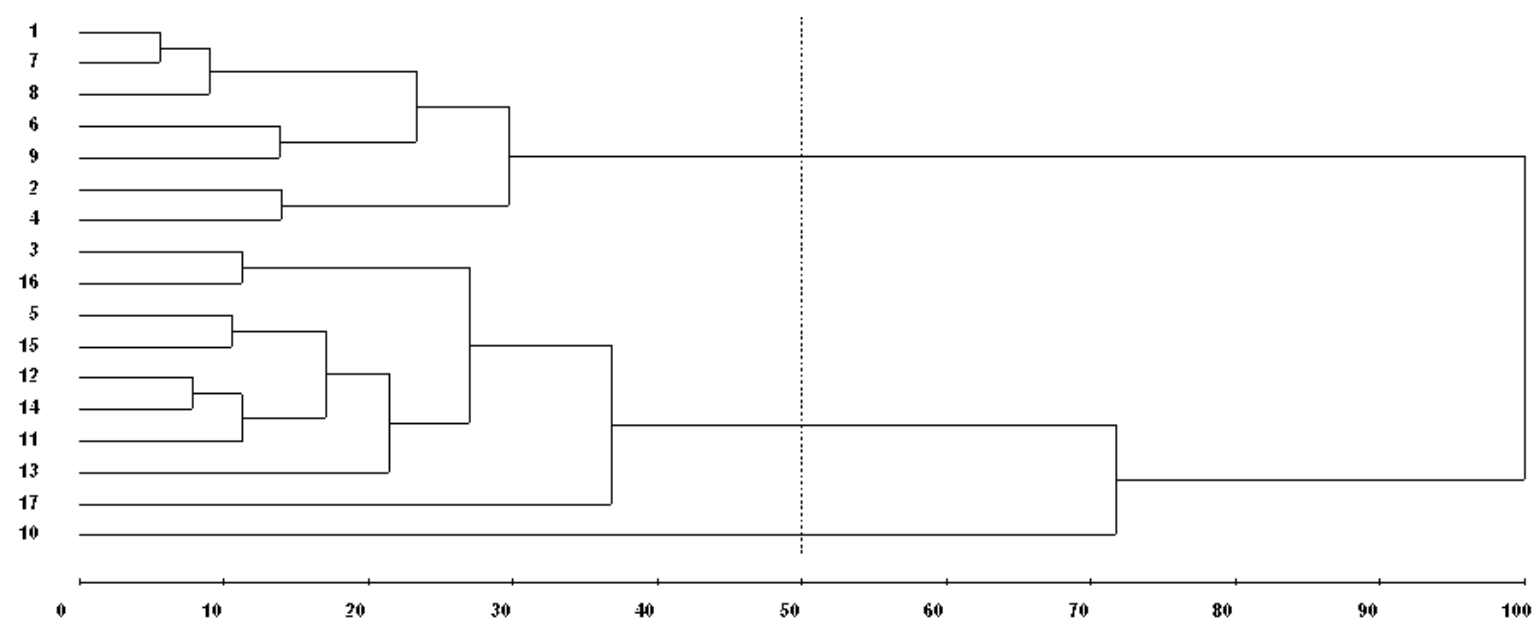

FIGURA 1 - Dendograma obtido a partir de 11 caracteres agronômicos, avaliados em 17 cultivares de girassol (1-Charrua; 2-Agrobel 962; 3-Agrobel 960; 4-Agrobel 972; 5-Dow M734; 6-Dow MG2; 7-Aguará 3; 8-Aguará 4; 9-Hélio 884; 10-Embrapa 122; 11-IAC Iarama; 12-Hélio 360; 13-Hélio 863; 14-Hélio 251; 15- Hélio 358; 16-Hélio 250; 17-Hélio 885) com base na distância de Mahalanobis ( $\left.D^{2}\right)$.

A análise de agrupamento, utilizando o método hierárquico aglomerativo da média entre os pares não ponderados (UPGMA) (Figura 1) apresentou correlação cofenética (r) 0,75. Esta análise, segundo Karasawa et al. (2005) é subjetiva e pode gerar alguma dificuldade na separação dos grupos, entretanto, é de fácil interpretação nas análises dos dados. Cruz (1990) sugere que o exame visual de pontos onde ocorram mudanças de níveis possibilita a delimitação dos grupos.
Desta forma, realizando-se o corte do dendograma em $50 \%$ de dissimilaridade (Figura 1), através de exame visual no ponto onde ocorrem altas mudanças de níveis, conforme sugere Cruz (1990), detectou-se a formação de três grupos.

No grupo I estão os cultivares Aguará 4, Dow MG 2, Agrobel 962, Hélio 884, Aguará 3, Charrua e Agrobel 972. No grupo II estão os cultivares Dow M734, Hélio 863, Hélio 251, Hélio 358, Hélio 360, Hélio 885, IAC larama, Agrobel 960 
VOGT, G. A. et al. Divergência genética entre cultivares de girasol...

e Hélio 250. E, no grupo III apenas o genótipo Embrapa 122. Não há nítida relação entre a separação dos grupos quanto a origem, tipo de cultivar e/ou empresa obtentora. Esse resultado é similar ao relatado por Arshad et al. (2007), entretanto divergente à análise de grupos efetuada por Amorim et al. (2007), o qual conseguiu detectar diferenças entre cultivares de origem argentina e brasileira, agrupando-os em grupos distintos.

As comparações das médias, para as onze características avaliadas e os grupos obtidos por meio da distância de Mahalanobis, permitem inferir sobre as diferenças entre os três grupos (Tabela 3 ). No grupo I estão os cultivares mais tardios e com porte mais alto, com DF entre 69 e 75 dias e AP entre 156 e $177 \mathrm{~cm}$, além de apresentarem maior NGC e REND. No grupo II estão os cultivares mais precoces e mais baixos, com DF entre 62 e 71 dias e AP entre 121 e $142 \mathrm{~cm}$. Embrapa 122 que formou um grupo isolado (Grupo III) foi o genótipo mais precoce entre os cultivares avaliados, apresentando porte baixo semelhante aos cultivares do grupo II.

TABELA 3 - Médias por grupo de Tocher dos 11 caracteres agronômicos avaliados para os 17 cultivares de girassol.

\begin{tabular}{|c|c|c|c|c|c|c|c|c|c|c|c|c|}
\hline Grupo & $\mathrm{n}^{\circ}$ cultivares & $\mathrm{AP}$ & $\mathrm{DH}$ & $\mathrm{NF}$ & $\mathrm{CC}$ & DF & MMA & NGC & $\mathrm{NCP}$ & $\mathrm{DC}$ & SCL & REND \\
\hline I & 7 & 167 & 19 & 33 & 3,0 & 72 & 43,5 & 905 & 1,00 & 16,9 & 0,5 & 1684 \\
\hline II & 9 & 134 & 18 & 30 & 3,6 & 65 & 46,3 & 708 & 1,00 & 15,9 & 3,3 & 1366 \\
\hline III & 1 & 141 & 16 & 30 & 5,0 & 59 & 57,3 & 611 & 0,87 & 14,9 & 26,8 & 1305 \\
\hline
\end{tabular}

Altura de planta (AP), diâmetro da haste (DH), número de folhas (NF), curvatura do caule (CC), dias para florescimento (DF), massa de mil aquênios (MMA), número de grãos por capítulo (NGC), número de capítulos por planta (NCP), diâmetro do capítulo (DC), porcentagem de capítulos com sintomas de podridão branca (SCL) e rendimento de grãos (REND).

A maior distância genética foi observada entre os cultivares Aguará 4 e Hélio $250(249,4)$ e a menor entre os cultivares Charrua e Aguará $3(6,6)$ (Tabela 4). A distância média entre todos os possíveis pares de cultivares foi de 77,62 . Os pares de cultivares mais dissimilares foram: 'Aguará 4 e Hélio 358', 'Aguará 3 e Embrapa 122', 'Aguará 4 e Embrapa 122', 'Charrua e Embrapa 122', 'Charrua e Hélio 250', 'Agrobel 960 e Aguará 4' e 'Dow MG2 e Hélio 250', ambos de diferentes empresas obtentoras/mantenedoras. Os cultivares mais semelhantes foram: 'Charrua e Aguará 3', 'Charrua e Aguará 4' e 'Hélio 360 e Hélio 251', ambas pertencentes à mesma instituição obtentora/ mantenedora. Em média, Embrapa 122 foi o mais divergente, e, Agrobel 962 o menos divergente em relação aos demais cultivares avaliados.

A análise para estimar a contribuição relativa de cada característica para a expressão da divergência genética indicou que os caracteres AP $(42,36 \%)$ e DF $(29,19 \%)$ foram os que mais contribuíram para a divergência total entre os 17 cultivares de girassol avaliados (Tabela 5). Os caracteres restantes, inclusive produtividade de grãos, apresentaram estimativas de S.j de pequena magnitude, entretanto, os cultivares do grupo I apresentaram maior NGC e REND (Tabela 5).

Quanto à análise por variáveis canônicas (VC), apenas duas (VC1 e VC2) foram suficientes para representar $83,90 \%$ da variância genética dos cultivares (Tabela 6). Segundo Cruz \& Regazzi (2001), quando as duas primeiras variáveis canônicas explicam acima de $80 \%$ da variação total, sua utilização é satisfatória no estudo da divergência genética por meio da avaliação da dispersão gráfica bidimensional dos escores em relação às variáveis canônicas (Figura 2).

Os grupos formados por meio da dispersão gráfica dos escores (Figura 2) foram coincidentes aos grupos formados nas análises de agrupamento, utilizando os métodos hierárquico aglomerativo da média entre os pares não ponderados (UPGMA) (Figura 1) e a distribuição dos grupos com padrões de comportamento similares pelo Método de Tocher (Tabela 2)

Os cultivares reunidos em grupos mais distantes (Tabela 2, Figura 1 e Figura 2) podem ser considerados como promissores em hibridações para formação de novas populações segregantes, contudo, é necessário que os genitores associem média elevada de produtividade e variabilidade para os caracteres que desejam ser melhoradas (Benin et al., 2002).

Associando os resultados obtidos neste trabalho e visando a formação de populações segregantes de girassol adaptadas às condições edafoclimáticas do Planalto Norte Catarinense, são sugeridos cruzamentos entre os cultivares mais produtivos do grupo I (Charrua, Aguará 3, Aguará 4, Dow MG 2, Hélio 884 e Agrobel 962) e as mais produtivas do grupo II (Dow M734 e Hélio 863). O cultivar do grupo III (Embrapa 122), apesar de ser divergente em relação as demais não é recomendado para ser utilizado em esquemas de hidridação ou seleção por apresentar características desfavoráveis, como alta SCL, baixo REND e CC vertical com haste ereta. 
VOGT, G. A. et al. Divergência genética entre cultivares de girasol...

TABELA 4 - Dissimilaridade entre os cultivares estimada pela distância de Mahalanobis $\left(D^{2}\right)$ em relação aos 11 caracteres agronômicos avaliados.

\begin{tabular}{|c|c|c|c|c|c|c|c|c|c|c|c|c|c|c|c|c|c|}
\hline $\mathrm{G}$ & 1 & 2 & 3 & 4 & 5 & 6 & 7 & 8 & 9 & 10 & 11 & 12 & 13 & 14 & 15 & 16 & 17 \\
\hline 1 & & 37,2 & 167,9 & 18,1 & 103,4 & 24,8 & $6,6^{(1)}$ & 7,4 & 31,8 & 212,0 & 137,1 & 116,9 & 144,7 & 98,7 & 131,7 & 211,5 & 93,3 \\
\hline 2 & & & 67,5 & 16,4 & 27,6 & 36,2 & 38,5 & 46,5 & 26,9 & 116,7 & 46,8 & 38,5 & 41,1 & 26,2 & 46,9 & 100,5 & 32,2 \\
\hline 3 & & & & 95,7 & 47,7 & 171,0 & 163,0 & 202,2 & 141,3 & 111,0 & 18,7 & 18,2 & 37,9 & 13,5 & 35,2 & 13,2 & 30,6 \\
\hline 4 & & & & & 67,2 & 45,9 & 27,6 & 35,6 & 35,8 & 162,0 & 79,0 & 69,4 & 86,9 & 49,1 & 86,3 & 134,8 & 41,8 \\
\hline 5 & & & & & & 70,5 & 102,9 & 114,0 & 56,6 & 79,7 & 27,1 & 21,0 & 31,0 & 19,1 & 12,4 & 59,1 & 48,8 \\
\hline 6 & & & & & & & 25,3 & 17,5 & 16,3 & 188,1 & 126,2 & 107,4 & 124,2 & 98,0 & 99,3 & 200,8 & 106,5 \\
\hline 7 & & & & & & & & 13,7 & 39,8 & 226,5 & 134,0 & 121,2 & 150,5 & 96,9 & 130,5 & 210,6 & 88,5 \\
\hline 8 & & & & & & & & & 24,4 & 224,2 & 158,5 & 139,5 & 156,4 & 122,3 & 152,5 & $249,4^{(2)}$ & 125,7 \\
\hline 9 & & & & & & & & & & 127,0 & 85,6 & 80,2 & 85,3 & 75,0 & 84,7 & 162,5 & 103,2 \\
\hline 10 & & & & & & & & & & & 57,2 & 62,5 & 55,8 & 90,0 & 64,4 & 89,0 & 146,1 \\
\hline 11 & & & & & & & & & & & & 12,7 & 20,4 & 13,7 & 19,7 & 21,0 & 45,5 \\
\hline 12 & & & & & & & & & & & & & 17,8 & 9,1 & 12,8 & 20,8 & 38,9 \\
\hline 13 & & & & & & & & & & & & & & 26,3 & 30,1 & 45,6 & 55,7 \\
\hline 14 & & & & & & & & & & & & & & & 20,5 & 32,1 & 19,0 \\
\hline 15 & & & & & & & & & & & & & & & & 30,5 & 43,5 \\
\hline 16 & & & & & & & & & & & & & & & & & 63,2 \\
\hline 17 & & 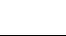 & 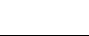 & 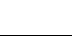 & & 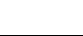 & & & & & & & & & & & \\
\hline
\end{tabular}

TABELA 5 - Contribuição relativa percentual dos caracteres para divergência $\left(D^{2}\right)$ analisada com base no critério de Singh (1981) entre 17 cultivares de girassol.

\begin{tabular}{lccc}
\hline \multicolumn{1}{c}{ Variáveis } & S.j & S.j $(\%)$ & S.j acum. (\%) \\
\hline AP & 4471,63 & 42,36 & 42,36 \\
DF & 3081,08 & 29,19 & 71,55 \\
NF & 823,78 & 7,80 & 79,35 \\
CC & 648,38 & 6,14 & 85,49 \\
MMA & 414,89 & 3,93 & 89,42 \\
NGC & 307,76 & 2,92 & 92,34 \\
DC & 288,22 & 2,73 & 95,07 \\
REND & 242,75 & 2,30 & 97,37 \\
NCP & 160,31 & 1,52 & 98,89 \\
DH & 106,98 & 1,01 & 99,90 \\
SCL & 10,42 & 0,10 & 100,00 \\
\hline
\end{tabular}

Altura de planta (AP), dias para florescimento (DF), número de folhas (NF), curvatura do caule (CC), massa de mil aquênios (MMA), número de grãos por capítulo (NGC), diâmetro do capítulo (DC), rendimento de grãos (REND), número de capítulos por planta (NCP), diâmetro da haste (DH) e porcentagem de capítulos com sintomas de podridão branca (SCL).

${ }^{1}$ S.j: contribuição da variável x para o valor da distância de Mahalanobis entre os cultivares $i$ e $i$ '. 
VOGT, G. A. et al. Divergência genética entre cultivares de girasol...

TABELA 6 - Variáveis canônicas obtidas da análise das variáveis originadas da transformação, por condensação pivotal, das variáveis originais e suas respectivas variâncias e a importância das variáveis do girassol nos autovetores.

\begin{tabular}{lcccc}
\hline $\begin{array}{c}\text { Variáveis } \\
\text { canônicas }\end{array}$ & Variância & Variância (\%) & $\begin{array}{c}\text { Variância } \\
\text { acumulada }(\%)\end{array}$ & $\begin{array}{c}\text { Importância das variáveis nos } \\
\text { autovetores }^{(1)}\end{array}$ \\
\hline VC1 & 26,15 & 67,39 & 67,39 & AP \\
VC2 & 6,41 & 16,51 & 83,90 & DH \\
VC3 & 2,19 & 5,64 & 89,54 & REND \\
VC4 & 1,36 & 3,50 & 93,04 & CC \\
VC5 & 1,03 & 2,65 & 95,69 & DC \\
VC6 & 0,53 & 1,38 & 97,07 & MMA \\
VC7 & 0,47 & 1,20 & 98,27 & DC \\
VC8 & 0,41 & 1,07 & 99,34 & NGC \\
VC9 & 0,14 & 0,36 & 99,69 & SCL \\
VC10 & 0,07 & 0,19 & 99,88 & NCP \\
VC11 & 0,04 & 0,12 & 100,0 & NGC \\
\hline
\end{tabular}

(1) Altura de planta (AP), diâmetro da haste (DH), número de folhas (NF), curvatura do caule (CC), dias para florescimento (DF), massa de mil aquênios (MMA), número de grãos por capítulo (NGC), número de capítulos por planta (NCP), diâmetro do capítulo (DC), porcentagem de capítulos com sintomas de podridão branca (SCL) e rendimento de grãos (REND).

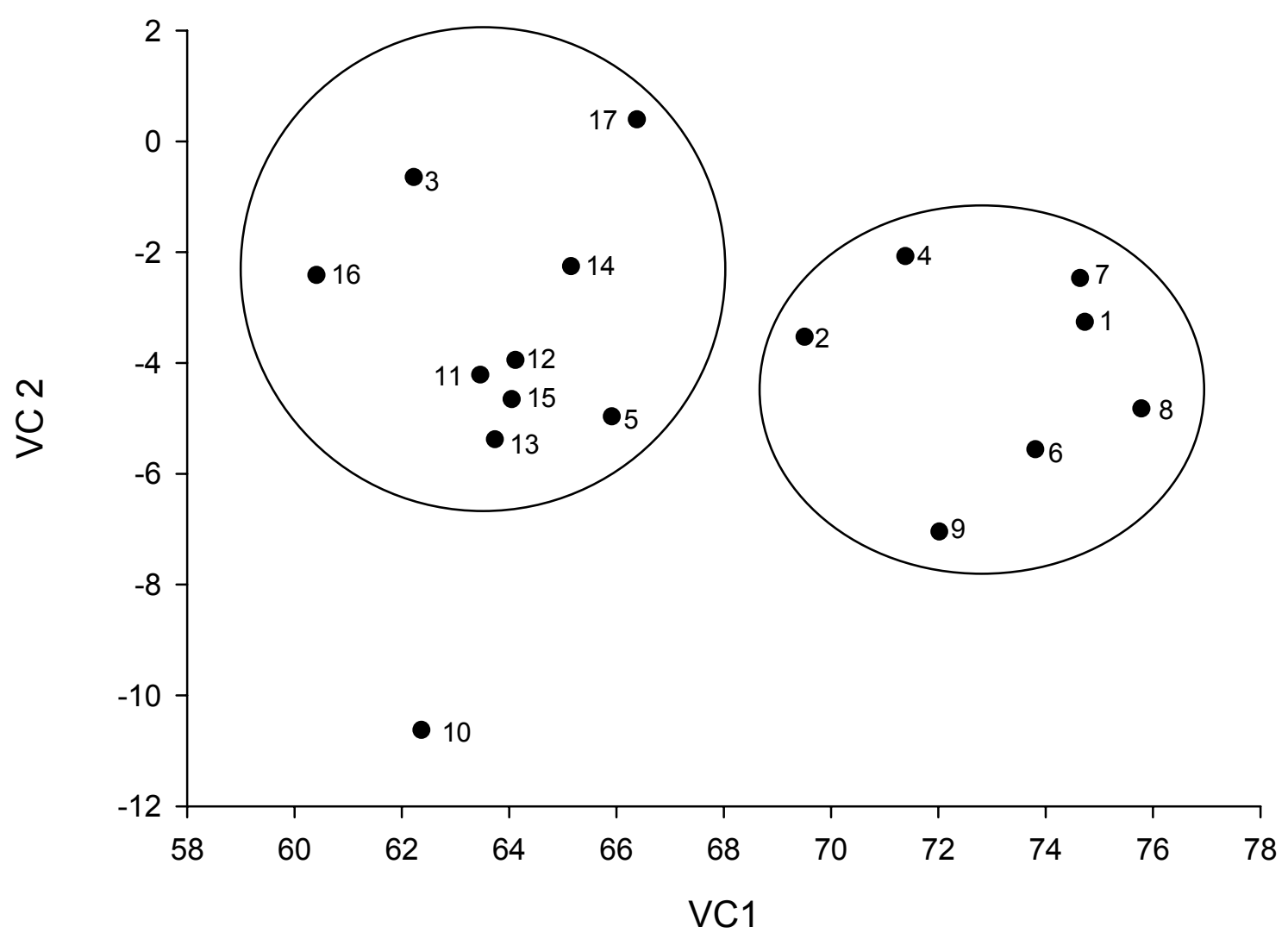

FIGURA 2 - Dispersão gráfica dos escores em relação aos eixos representativos das variáveis canônicas (VC1 e VC2) relativos a 11 caracteres agronômicos avaliados em 17 cultivares de girassol. (1-Charrua; 2-Agrobel 962; 3-Agrobel 960; 4-Agrobel 972; 5-Dow M734; 6-Dow MG2; 7-Aguará 3; 8-Aguará 4; 9-Hélio 884; 10-Embrapa 122; 11-IAC larama; 12-Hélio 360; 13-Hélio 863; 14-Hélio 251; 15 - Hélio 358; 16-Hélio 250; 17-Hélio 885). 
VOGT, G. A. et al. Divergência genética entre cultivares de girasol...

\section{CONCLUSÕES}

Os 17 cultivares de girassol avaliados foram divergentes e agrupados em três grupos distintos de acordo com as técnicas de análise multivariada baseados no agrupamento de Tocher,
UPGMA e variáveis canônicas. Foi possível identificar possíveis cruzamentos promissores entre os cultivares, visando a formação de populações segregantes e posterior desenvolvimento de variedades adaptadas as condições edafoclimáticas do Planalto Norte Catarinense.

\section{REFERÊNCIAS}

1. AMORIM, E. P. et al. Divergência genética em genótipos de girassol. Ciência e Agrotecnologia, v. 31, n. 6, p. 16371644, 2007.

2. AMORIM, E. P. et al. Correlações e análise de trilha em Girassol. Bragantia, v. 67, n. 2, p. 307-316, 2008.

3. ARSHAD, M.; ILYAS, M. K.; KHAN, M. A. Genetic divergence and path coefficient analysis for seed yield traits in sunflower (Helianthus annuus L.) hybrids. Pakistan Journal of Botany, v. 39, n. 6, p. 2009-2015, 2007.

4. BACKES, R. L. et al. Desempenho de cultivares de girassol em duas épocas de plantio de safrinha no Planalto Norte Catarinense. Scientia Agraria, v. 9, n. 1, p. 41-48, 2008.

5. BALBINOT JR., A. A.; BACKES, R. L.; SOUZA, A. M. de. Desempenho de cultivares de girassol em três épocas de semeadura no Planalto Norte Catarinense. Scientia Agraria, v. 10, n. 2, p. 127-133, 2009.

6. BENIN, G. et al. Comparações entre medidas de dissimilaridade e estatísticas multivariadas como critérios no direcionamento de hibridações em aveia. Ciência Rural, v. 33, n. 4, p. 657-662, 2003

7. BENIN, G. et al. Identificação da dissimilaridade genética entre genótipos de feijoeiro comum (Phaseolus vulgaris L.) do grupo preto. Revista Brasileira de Agrociência, v. 8, n. 3, p. 179-184, 2002.

8. BERTAN, I. et al. Comparação de métodos de agrupamento na representação da distância morfológica entre genótipos de trigo. Revista Brasileira de Agrociência, v. 12, n. 3, p. 279-286, 2006.

9. BERTINI, C. H. C. M.; TEÓFILO, E. M.; DIAS, F. T. C. Divergência genética entre acessos de feijão-caupi do banco de germoplasma da UFC. Revista Ciência Agronômica, v. 40, n. 1, p. 99-105, 2009.

10. BRUGINSKI, D. H.; PISSAIA, A. Cobertura nitrogenada em girassol sob plantio direto na palha: II - morfologia da planta e partição de massa seca. Scientia Agraria, v. 3, n. 1-2, p. 47-53, 2002.

11. CARGNELUTTI FILHO, A. et al. Comparação de métodos de agrupamento para o estudo da divergência genética em cultivares de feijão. Ciência Rural, v. 38, n. 8, p. 2138-2145, 2008.

12. CRUZ, C. D. Aplicação de algumas técnicas multivariadas no melhoramento de plantas. 1990.188 f. Tese (Doutorado em Genética e Melhoramento de Plantas) - Escola Superior de Agricultura Luiz de Queiroz, Universidade de São Paulo, Piracicaba.

13. CRUZ, C. D. Programa Genes: diversidade genética. Viçosa: UFV, 2008. 278 p.

14. CRUZ, C. D.; REGAZZI, A. J. Modelos biométricos aplicados ao melhoramento. 2. ed. ver. Viçosa: UFV, 2001. 390 p.

15. ELIAS, H. T. et al. Variabilidade genética em germoplasma tradicional de feijão-preto em Santa Catarina. Pesquisa Agropecuária Brasileira, v. 42, n. 10, p. 1443-1449, 2007.

16. EMPRESA BRASILEIRA DE PESQUISA AGROPECUÁRIA (EMBRAPA). Centro Nacional de Pesquisa de Solos. Sistema brasileiro de classificação de solos. Brasília: Embrapa Produção de Informação; Rio de janeiro: Embrapa solos, 1999. $412 \mathrm{p}$

17. IDE, B.Y. et al. Zoneamento agroclimático do Estado de Santa Catarina: $2^{\mathrm{a}}$ etapa. Florianópolis: EMPASC, 1980. 160

18. KARASAWA, M. et al. Aplicação de métodos de agrupamento na quantificação da divergência genética entre acessos de tomateiro. Horticultura Brasileira, v. 23, n. 4, p. 1000-1005, 2005.

19. MESSETI, A. V. L.; PADOVANI, C. R. Estudo da divergência genética em girassol por meio de técnicas multivariadas. Revista Energia na Agricultura, v. 24, n. 2, p. 14-28, 2009.

20. MIRANDA, G. V. et al. Potencial de melhoramento e divergência genética de cultivares de milho-pipoca. Pesquisa Agropecuária Brasileira, v. 38, n. 6, p. 681-688, 2003.

21. MOHAN, G. S.; SEETHARAM, A. Genetic divergence in lines of sunflower derived from interspecific hybridization Sabrao Journal of Breedind and Genetics, v. 37, n. 2, p. 77-84, 2005

22. MOURA, W. M. et al. Divergência genética de linhagens de pimentão em relação a eficiência nutricional de fósforo. Pesquisa Agropecuária Brasileira, v. 34, n. 2, p. 217-224, 1999.

23. PORTO, W. S.; CARVALHO, C. G. P. de; BARTH PINTO, R. J. Adaptabilidade e estabilidade como critérios para seleção de genótipos de girassol. Pesquisa Agropecuária Brasileira, v. 42, n. 4, p. 491-499, 2007.

24. SANTOS, R. C. et al. Classificação de genótipos de amendoim baseada nos descritores agromorfológicos e isoenzimáicos. Ciência Rural, v. 30, n. 1, p. 55-59, 2000.

25. SOCIEDADE BRASILEIRA DE CIÊNCIA DO SOLO. Manual de adubação e calagem para os Estados do Rio Grande do Sul e de Santa Catarina. 10. ed. Porto Alegre: SBCS/Núcleo Regional Sul; Comissão de Química e Fertilidade do Solo - RS/SC, 2004. 394 p.

26. SUBRAHMANYAN, S.V.R.; KUMAR, S.S.; RANGANATHA, A.R.G. Genetic divergence for seed parameters in sunflower (Helianthus annuus L.). Helia, v. 26, n. 38, p. 73-80, 2003.

27. VIEIRA, E. A. et al. Emprego de modelos gráficos na seleção de genitores de milho para hibridização e mapeamento genético. Ciência Rural, v. 35, n. 5, p. 986-994, 2005.

Recebido em 21/10/2009

Aceito em 24/05/2010 
